\title{
Risk Factors for Recidivism in Juvenile Criminal Offenders
}

\author{
Suncica Dimitrijoska PhD \\ University "St. Cyril and Methodius" Faculty of Philosophy, \\ Skopje, Institute of Social Work and Social Policy "Mother Teresa" - Skopje
}

Buzarovska, Gordana PhD

University "St. Cyril and Methodius" Law Faculty "lustinianus Primus", Skopje, Macedonia

Zorica Saltirovska PhD

University "St. Cyril and Methodius" Faculty of Philosophy, Skopje, Institute of Security, Defence and Peace, Skopje

\begin{abstract}
In the Republic of Macedonia, very few authors are actively working on classification, evaluation, and criteria for choice of treatment of juvenile delinquents, while others are working on the evaluation of the treatment and implementation of new forms and types of interventions. On the one hand, the imperfect intervention models, and on the other hand, inadequate scientific methodology, are oftentimes factors contributing to a state which leads to problems and intervention models that are created and evaluated in one socio-cultural environment, and implemented in another environment, much more different to the former. The penological analysis of recidivism is concerned with two types of factors, such as inadequate social reaction - an improper criminal sanction, and inadequate treatment and unsuccessful process of resocialization, i.e. inadequate treatment in the facility where the sanction is being endured (Boshkovic, M., 2006). The abundance of studies conducted on the topic have all shown that the lack of parental support and mutual trust are closely correlated to the phenomenon of juvenile delinquency, which in time could lead to re-offending and recidivism. The focus of the current study is to validate the assessment instrument used by the Department of Juvenile Justice to determine a referred youth's risk to re-offend.
\end{abstract}

Keywords: recidivism, child, risk factors

\section{Introduction}

The validation of an assessment or instrument used in the prediction of risk to recidivate is critical to ensure the predictions that come from that instrument and the recommendations made based on the predictions are indeed the best possible. The first step to being able to provide effective treatment to juvenile offenders is the use of a validated risk/needs assessment to determine the risk level ofthe youth, which determines the needed intensity of treatment, and the individualizedcriminogenic needs, which must be targeted in order to reduce the likelihood of recidivism. Beyond the importance of the safety and security of theyouth served, one of the most challenging tasks for a criminal justice agency of that magnitude isto ensure the provision of appropriate, evidence-based treatment services to the youth referred inan effort to reduce their risk of re-offending and increase public safety. A critical step toproviding empirically proven, appropriate treatment to a juvenile offending population is theimplementation of an evidence-based, validated risk/need assessment.

Republic of Macedonia as a developing country, experiences a lot of parallel processes that have impact on the overall life of the children. The number of children in conflict with the law is constantly rising, as well as the number of re-offenders, which indicates that there is a need for conducting scientific research on this problem in order to determine the reasons for this phenomenon and if possible, to find appropriate programmes for reduction and prevention of this phenomenon. 
Recidivism at children perpetrators of crimes, is not properly followed, although it is widely present, and it is not reducing and it becomes a threat, for the children themselves being perpetrators of crimes, as well as for the society as a whole. The problem becomes more complex and quite frequently it is combined with other severe forms of social pathology, drugs, violent behavior, committing group crimes, etc., which indicates that the problem is not properly taken care of, namely, there is just declarative commitment without being accompanied with institutional or financial supportive measures.

The absence of good data about the number of children who appear as reoffenders, and the increased number of such children, indicates that there is a need for undertaking scientific research to determine the causes for this phenomenon and to propose appropriate interventions for overcoming this significant challenge.

Only few authors deal with the issues such as classification, appraisal or criteria for selection of appropriate treatment, while others investigate the evaluation of the treatment and introduction of new types and forms of interventions. The imperfect intervening models on one hand and the scientific methodology on the other hand, are the frequent factors for a situation which frequently results with problems in undertaking appropriate action and intervention models created and evaluated in a socio-cultural environment with specific population, very different from the conditions in it.

In the scientific literature (Milutinović, 1976, Singer, 1996, Lakićević, 2000, Buljubašić, 2008) the recidivism at children in conflict with the law is marked as definite indicator for unsuccessful re-socialization measure or lack of appropriate social measures, which is common feature of all recidivisms, regardless of other divisions, meaning that the criminal sanction or other alternative forms of social reactions for the first crime or previously committed crimes, did not give positive results and the children continued to commit other crimes.

The penological analysis of recidivism speaks about two types of factors, such as inappropriate social reaction - improper selection of criminal sanction, inadequate treatment and unsuccessful process of resocialization, that is, inappropriate treatment in educational-correctional institutions where the sanction is taking place.

In penological sense, recidivism indicates that the sentence and the provided treatment in the institution did not give positive results in terms of resocialization (lilić Z., Jovanić G., 2011).

The conducted researches indicate that recidivism usually happens in a period of one year after the committed crime. The children that perpetrate crimes in violent manner are more prone to recidivism. Some research studies indicate that if the child has started with crimes early in his/her life, there is higher probability that the child would become violent and chronic perpetrator of crimes when he/she would grow up.

The skills for committing crimes increase with each perpetrated crime. The reoffenders that have committed more crimes in a shorter period of time are called chronic reoffenders.

Recidivism is also determined according to the time interval between two events, that is from the time from leaving the institution until the moment when the reoffending happened. So for example, many researches done on programmes for recidivism showed „recidivism rate of one year "namely the participants in the programme most frequently committed crime again in a period of one year after they left the correctional institution.

The time interval represents a summary of the following intervals: from leaving the correctional institution until the moment of apprehension, from the moment of apprehension until the moment of interrogation, from the moment of interrogation until the moment of the trial, from the trial until the sentence and from the sentence until the perpetration of the next crime. Only the first interval refers to criminal behavior, all the others are reflection of the legal system.

The answers from the interviews with the members of the expert team from the Centre for social work, in terms of the selection of sanctions, showed that most of them think that the sanctions are well selected, but there are problems in regard to the implementation of the sanctions $85 \%$. If we take in consideration that part of the sanctions are not applicable $11 \%$, due to lack of possibilities for alternative measures, the general useful work although required, is not frequently used as a measure.

The children who are perpetrators of crimes or reoffenders in conflict with the law, are given different sanctions in order to reduce the chances for recidivism. In compliance with the Law on justice for children (Official Gazette of RM 148/2013), the children in conflict with the law are most frequently sentenced with different educational measures and the most frequent of those is enhanced supervision represented with $77,14 \%$, followed by disciplinary and institutional measures. The financial 
penalties and imprisonment are the rarest ones with $17,15 \%$. In our case, the alternative measures and the safety measures are not given by the responsible institutions.

The data from the research conducted for children that are sentenced with institutional measure and imprisonment showed that $74,2 \%$ are reoffenders. $46 \%$ of them perpetrated crime with the same group (social multiple recidivism), $17,8 \%$ of the children committed crime in a different group (general multiple recidivism), $8 \%$ of the children perpetrated the same crime (common special recidivism) and one child is perpetrator of crimes in a different group (general common recidivism). The most frequent one is the special multiple recidivism (Kitkajn,2014).

The recidivism is frequently linked with the effects of the reaction of the community towards the children in conflict with the law. In the Criminal Code of the Republic of Macedonia, the reaction of the society goes from non-initiation of proceeding against children with the application of the principle of opportunity, to educational measures and criminal sanctions as the last option. Alternative measures have been introduced so the children would not enter in the criminal legislation system when that is required and possible, in order to avoid stigmatization of the children.

It's quite worrying that over one third of the total analyzed cases, 33\%, the children reoffenders were at the age below 14 , with particular representation of children at the age of $13(18 \%)$ out of all analyzed cases.

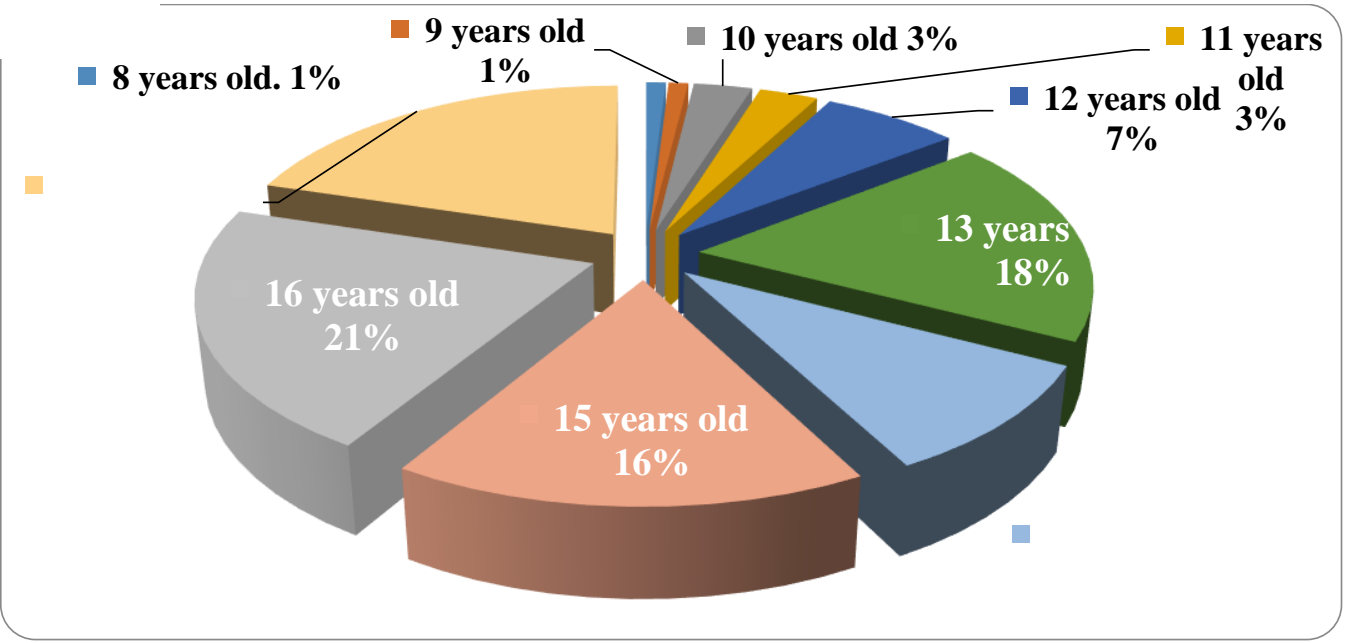

Chart No. 1: The age of the child at the time of the first perpetrated crime (Risk factors for recidivism, Council for Prevention, Buzarevska G., Dimitrijoska S,, 2015)

The knowledge, skills and the attitudes of the employees are of utmost importance for the process of support to children in conflict with the law, in terms of creation of appropriate interventions and overcoming the risks.

The level of knowledge in the area of social protection, of the members of the professional teams in the institutions that work with children is very different, ranging from basic knowledge in this area, to advanced knowledge in the area of with children in conflict with the law.

From the conducted interviews with the expert personnel it can be concluded that they recognize their weaknesses such as overload of work, insufficient education and training of some of the staff in the area of work with children in conflict with the law, small number of professional service providers in the institution, lack of technical conditions (premises and conditions for conducting field work, and visits to the families of the children.

\section{Instruments /techniques used in the process of appraisal}

For purpose of assessing the child and the family relations and interactions, and the parental capacities, special questionnaires were designed, such as grading of housing conditions, map for social networks, culturegrams, questionnaire for strengths and weaknesses in terms of the emotional and social relations, scale for assessment of hyperactivity and 
attention deficit. There is also questionnaire for parental supervision and scale $\mathrm{u}$ for day-to-day difficulties of the parents, family activities and time line for the events in the family. The techniques are used depending on the choice of the service provider. Although the development of the genogram is an obligation of the team in compliance with the guidelines provided by the Institute for social work, it is rarely developed in practice.

The Institute for social work has developed standardized techniques, tests (health, development, mental-health, educational and other instruments for appraisal of the needs) for assessment of the personality and risks that the child is exposed to, as well as the capacities of the child and his/her family. The instrument for assessment of the risk at children that are given educational measures is not developed.

The instrument for assessment of the risks for recidivism and the needs of convicted persons/children is developed. The application of the instrument is supported with manual developed by the Directorate for execution of sanctions of the Republic of Macedonia for purpose of improving the resocialization and successful reintegration in the society. The instrument for assessment of the risk and needs of the convicted children contains open-ended and closed-ended questions divided in 10 areas.

Criminal trends - it refers to the perpetrated crime that plays important role in the prediction of possible recidivism, but there is also data about the previous behavior of the convicted person/child. This area is represented with $15 \%$ within the overall factors that have impact in the appraisal of the risk.

Mental disorders of the person - it refers to socialization of the child, inherited factors, development crisis. Through this area it is possible to obtain information about possible short-term or significant mental disorders in the anamnesis of the convicted child, possible disorders in the childhood period and the adolescence, asocial characteristics, intellectual abilities and possible consumption or addiction to drugs, alcohol or pills. The presence of this factor within the overall factors equals to $15 \%$.

Understanding of the illness or disorder - it is important part in the creation of the picture for the convicted child, his/her understanding and acceptance of the others and the world in general and itself, which is very important for the implementation of the Plan for individual work with the beneficiary/child. Whether the behavior of the child is real or it is such only to obtain specific treatment benefits? This area is represented with $5 \%$ within the overall assessment of the convicted child.

Specific conflict behavior - the objective in this area is to obtain information about the perpetration of the crime; what is the reason for the crime (whether it is some specific conflict situation); whether the convicted child has a high or low level of tolerance of frustration for overcoming specific conflicts or undefined indicators in the area of conflict behavior that might have impact on the assessment of the risk for recidivism. The Aggression domain is next, which measures tolerance for frustration, hostile interpretation of the actions and intentions of others, and belief that yelling or belief that fighting resolves disagreements. This area is represented with $10 \%$ within the overall factors of impact in the risk assessment.

Social skills - this area covers the aspects which are linked with the current living style of the convicted child, who does he/she spends time with, are there any stabile friendships, how does he/she spends the free time, does the child in conflict with the law have twisted perception about the social reality, what are his/her communication skills, etc. The final domain examines skills that could potentially help the youth to avoid anti-social behavior. These skills include the ability to recognize that there are consequences to one's actions, ability to set realistic goals, ability to apply appropriate solutions and problemsolving and situational perception. This area covers $15 \%$ of the overall appraisal from the application of the instrument.

Criminal history - it refers to the number and the type of the committed crimes by the convicted child, his/her attitudes, perceptions and behavior, whether the person is a primary perpetrator and if there are other forthcoming proceedings against the child. This area is represented with $15 \%$ within the overall assessment and it plays important role within the overall assessment of the risks for recidivism.

Assessment of the youth's prior criminal history. It includes information on the age at which the youth first made offense, seriousness of prior offenses in terms of number of prior felonies and prior misdemeanors, prior commitment placements, prior escapes, and the type of offenses (such as weapon, against person, and sex offenses). 
Facing the fact - it is an area which refers to the preparedness of the convicted child realistically to face the penalty and during the treatment phases, to develop realistic feeling to resolve the consequences. This area participates with $5 \%$ within the overall factors covered in the appraisal.

Options for treatment - this area refers to the determined needs for treatment, the preparedness of the convicted person to accept the treatment or the existence of resistance or conditions and opportunities in the institution for efficient treatment of the convicted child. This area participates with $5 \%$ in the assessment of the risk and it has general impact on all indicators of the instrument.

Preparation for treatment - this is very important area which is aimed to ensure information about the preparation of the convicted child for treatment. The acceptance of the treatment by the convicted child and his true preparedness for the treatment, means also acceptance of the planned treatment activities which are to be implemented in the course of the serving of the sentence. This area participates with $10 \%$ of the grade of the assessment.

The preparation for releasing the child is an important segment of the risk assessment of the convicted children, since it is linked with the family and the involvement of the child in the family life, planning of the income, accommodation, planning of the future of the child, whether the convicted child accepts assistance and support from other institutions, etc. If these indicators are not properly treated, there is high risk for recidivism.

The self-assessment questionnaire for the convicted child is a comparative instrument which is used to evaluate the needs of the convicted child and for assessment of the risk and his/her subjective awareness about his/her needs and problems. This instrument enables the convicted child to recognize his/her feelings, priority needs and to obtain the overall picture about himself/herself. The self-assessment questionnaire for the convicted child is comprised of four parts:

personal data;

assumptions which, if fulfilled would mean that the child would stop committing crimes;

factors which have an impact on the behavior or represent a cause for his/her criminal behavior and problem for normal functioning;

things which are needed to the convicted child (writing, reading, depression, loneliness, anger (stress, housing).

The conducted survey in 2015 with representative sample of 35 children that serve sentence in prison in the Penitentiary in Tetovo and the Penitentiary in Ohrid showed that there is a high risk for repeated recidivism at $26 \%$ of the children, $34 \%$ of the children are exposed to low risk for recidivism and $40 \%$ of the children have middle size risk for recidivism. Having in mind that there isn't any child with very low risk for recidivism, it can be concluded that the risk for recidivism is present among all the children who are spending time in prison.

The educational aspect of the children within the survey indicates that $43,28 \%$ of the children that serve time in prison are illiterate, $17,1 \%$ of the children have incomplete primary education and about the same percentage of the children have completed primary education and only $2,86 \%$ of the children are with completed secondary education.

In terms of working habits $51,44 \%$ of the children did not have working habits, $42,84 \%$ of them had partially developed working habits and only $5,72 \%$ of the children have developed working habits (Kralevska B, 2015). This indicates the high risk for recidivism at children who are spending time in prison.

The intersectoral cooperation is present between the Centre for Social Work and other authorities or organs that represent different relevant ministries (police stations, medical centres, schools, schools, the Public Prosecutor's Office, the Court), local self-government and NGO's that work in the area of protection of children. This cooperation is linked with the implementation of the Law on Justice of Children (so called,cooperation in the line of duty"). There is a Protocol for implementation of the Law on Justice of Children which regulates this cooperation in more precise and efficient manner, in terms of the roles and responsibilities of the partners in the implementation of activities regulated by the law.

The good cooperation among the partners is an important factor for the Centre for Social Work in the process of implementation of activities with children in conflict with the law for ensuring support to the children and their respective families. 
The involvement of partners in the appraisal, and in the implementation of sanctions is of different intensity due to the complexity of the problems and the individual needs of the children in conflict with the law.

The mentoring programme helps for reducing the high level of recidivism. The core concept is to develop alternative models for provision of support to children with their active participation in order to ensure the process to be in their best interest.

The mentoring programme was introduced for the first time in the Republic of Macedonia in 2010, as pilot project - project in frames of the Justice for Children Project financed by the European Union and co-financed by UNICEF. In a period of one year, the programme paired students with children with children in conflict with the law who required assistance for new beginning in life. The pilot programme gave excellent results - there was not a single re-offender among the children included in the programme. The programme was continued in 2013, with inclusion of the centres for social work from Veles and Kumanovo and with participation of many mentors, and today the programme is part of the Programme for social protection which every year is passed by the Government.

\section{Recommendations}

There is a need for development of methodology for monitoring/evaluation of the process of work with children at risk or children perpetrators of crimes. In the report on prevalence of crime among children it can be seen that up to $87,1 \%$ of the children appear as perpetrators of several crimes.

While many young adults who come into contact with the juvenile and criminal justice system there remains a population of young adults who are at moderate to high risk of reoffending under the supervision of both systems. Given the scarcity of research on what works for these young adults, few states have targeted strategies specifically at reducing recidivism and improving other outcomes for this population. The following recommendations are intended to address this gap and help state policymakers, agency leaders, researchers, and the field to advance policies and practices that can help these young adults transition to a crime-free and productive life.

Recommendation: Tailor supervision and services to address young adults' distinct needs

Both juvenile and adult criminal justice system leaders should ensure that services and supervision for young adults are developmentally appropriate and address the distinct needs of this population. While research findings are limited, existing literature and consultations with experts and practitioners in the field identified the following elements that will likely need to undergird any effective strategy for improving outcomes for young adults under justice system supervision:

- Targeted cognitive behavioral approaches to address criminal thinking and antisocial behavior

- Career pathways that integrate education, vocational training, and job-readiness supports to ensure that young adults are prepared to join and succeed in the workforce

- Targeted mental health and substance use treatment so that young adults are better able to manage their conditions

- Life skills training to ensure that young adults are ready to transition to independence

- Family involvement or connection to a supportive adult to help young adults navigate the difficult transition to adulthood regardless of the strategy employed to improve outcomes for young adults, it will only succeed if justice system professionals are equipped to successfully engage and work with this population. All staff that interact with young adults, including corrections, parole, and probation staff, should receive ongoing training on how interventions should be tailored to young adults' distinct needs.

Policymakers should require and fund agencies to analyze recidivism data by the following additional variables, listed in priority order, to understand system effectiveness:

- Youth demographic groups, so juvenile justice systems can identify deficits in system performance for youth who share certain characteristics or come from specific geographic areas.

- Placement type, facility, service provider, and length of stay, so juvenile justice systems can know which providers are generating recidivism reductions; how long it takes to produce such outcomes(and when more time spent in services/facilities doesn't produce better results); and where opportunities exist to use system resources more efficiently. 
- Youth's service needs and programs, to understand how best to prioritize resources within the juvenile justice system and across other service systems to address youth's needs and ensure that these resources are used only for interventions that address these needs effectively, with resulting reductions in recidivism.

\section{References}

[1] Arnaudovski, Lj. (1984): Juvenile delinquency, Skopje, pg. 25;

[2] Buzharovska - Lazhetich, G.(2011): Authorizations of the centres for social work and the public prosecutor in the area of juvenile justice, Code, Faculty of Law Zagreb, 61, (2) pg.441-468;

[3] Buzharovska, G., Misoski, B.: Reforms of the criminal law and respect of the human rights - preparations for comprehensive application of the new Code of Criminal Procedure, Research project "Negotiation and Mediation". Skopje: Association of Criminal Law and Criminology of Macedonia, 2009;

[4] Buzharovska, G., Nanev, L., Koshevaliska, O. (2012): International documents for implementation of juvenile justice, Council for Prevention of Juvenile Delinquency, Kavadarci;

[5] Binder, A., Geis, G., Dickson D Bruce Jr.(2001): Juvenile Delinquency: Historical, Cultural \& Legal Perspectives, Elsevier, pg.4;

[6] Burfeind, J., Bartusch, D., (2011): Juvenile Delinquency: An Integrated Approach, Jones \& Bartlett Learning;

[7] Cipriani, D.J., (2007): Children's Rights and the Minimum Age of Criminal Responsibility - A Global Perspective, VRIJE UNIVERSITEIT, pg. 282 - 300;

[8] Davitkovski, B., Buzharovska, G., Kalajdziev, T., Mickovikj, D.:(2010): Comparative Review of domestic legislation and the Convention on the Rights of the Child - Skopje: Ministry of Justice, pg.8-16;

[9] Dimitrijoska S.,(2012) Social work with juveniles perpetrators of crime, Faculty of Philosophy, Skopje;

[10] Dimitrijoska S., (2012) Mentoring Programme, Faculty of Philosophy, Skopje;

[11] Dünkel, F., Pruin, I. (2008): Community Sanctions and the Sanctioning Practice in Juvenile Justice Systems in Europe, Reforming Juvenile Justice, (eds. Junger-Tas/ Dünkel), Springer, pg. 183-204;

[12] Kambovski, V.(2006): Criminal Law, general part, 2 August Shtip, pg. 804;

[13] Kralevska B.(2015), Assessment of the needs and the risks for recidivism at persons doing time in prison for children or institutional measure referral to educational juvenile correctional centre (master thesis) Faculty of Philosophy Skopje;

[14] Stojanović-Milošević, G. (2006) „Criminal-legal status of a juvenile in the legislation systems of the former Yugoslav republics", Macedonian review for criminal law and criminology, year 13, no 2, pg. 3;

[15] Rulebook for maintaining evidence of beneficiaries of social protection and documentation for expert work (Official Gazzette of the Republic of Macedonia No.171/11);

[16] Law on Juvenile Justice, Official Gazzette of the Republic of Macedonia No.148/2013; 